\title{
Primeros apuntes sobre la Lima de Palma en las lecturas de Porras y Salazar Bondy
}

Por Harry Belevan-McBride ${ }^{1}$

l Discurso en ocasión de su incorporación como Miembro de Número del Instituto Ricardo Palma, el 11 de octubre del 2013, en el Centro Cultural Ccori Wasi de Miraflores. 
Fue embajador del Perú en Portugal, Bolivia, Eslovenia, Eslovaquia, Mónaco, Austria, Francia y en la Unesco. Actualmente es miembro de número de la Academia Peruana de la Lengua y director ejecutivo del Instituto Raúl Porras Barrenechea. 
Se determina hoy mi ingreso como numerario del Instituto Ricardo Palma y por ello expreso, en primer lugar, mi reconocimiento a los amigos que me han invitado a integrar esta academia dedicada al estudio y difusión de la obra de quien, con justicia, es llamado el patriarca de nuestras letras. Ellos han creído, sugestionados por el afecto más que por la convicción, que yo podría alguna vez convertirme en un intérprete de Palma algo más aprovechado que el mero lector, dichoso pero acrítico, que he sido hasta ahora. Sin embargo, han pasado inadvertidamente por alto que el apego a nuestro tradicionista es un sentimiento consustancial a todo limeño, o cuando menos a los que no renegamos de nuestra ciudad, como instiga la demagogia mal llamada progresista según la cual la peruanidad estaría en los valores vernáculos de las provincias antes que en los supuestamente postizos de Lima. Agradezco, entonces, al doctor Iván Rodríguez Chávez, Rector de la Universidad Ricardo Palma y al doctor Manuel Pantigoso, flamante Presidente de este Instituto, por la dignidad que me confiere esta casa de estudios superiores, de la que ya tengo el privilegio de ser profesor honorario, aceptándome hoy como miembro de Número del Instituto Ricardo Palma. Tan generosa decisión compromete desde ahora mi más esforzado empeño por obtener algún día las credenciales suficientes que justifiquen la confianza que ellos depositan en mí.

No todo, sin embargo, podía ser grato o festivo en este día, pues el año 2013 en que estoy ingresando al Instituto también marca la fecha del deceso de su primer presidente, don Estuardo 
Núñez, aquel maestro de generaciones que partió hace pocas semanas dejando detrás suyo una obra tan multifacética como ancha y propia fue su vida, obra en la que la exégesis de nuestro tradicionista y la reflexión erudita sobre su legado encontraron un lugar preeminente. Quienes tuvimos la fortuna de ser sus alumnos recordamos siempre esas enseñanzas suyas, que fueron y seguirán siendo aportes perdurables al estudio de la literatura peruana y al ejercicio inagotable que constituye el comentario palmista. Mi más respetuoso homenaje a esta figura señera de nuestras letras que fue don Estuardo Núñez.

Próximos a celebrar el decimosexto aniversario de la creación del Instituto Ricardo Palma, vengo esta tarde a compartir con ustedes unas notas iniciales sobre el insigne autor de las Tradiciones Peruanas o, más propiamente hablando, a participarles lo que he denominado con intencional mesura, Primeros apuntes sobre la Lima de Palma en las lecturas de Porras y Salazar Bondy.

Fuere solo por pudoroso recato frente a la magnitud del reto, o bien por incauta pirueta estilística que presumiría modestia de propósito, lo cierto es que con frecuencia se llama "apuntes" a ciertos escritos sobre temas océanos, como acostumbro calificar a las materias inmensas, como una forma de guarecernos de las probables lagunas en el rigor de las pesquisas o de las posibles carencias en las consiguientes glosas. Ricardo Palma es uno de esos temas océanos, una materia inconmensurable al igual que Lima. Y tanto se ha discurrido sobre ambos que, sospecho, bien podría resultar hasta temerario cualquier intento de hallar algún rasgo interpretativo que arroje siquiera una pálida luz de ínfula innovadora sobre este escritor fundacional del Perú y sobre la ciudad síntesis del país. Por todo ello es que, en este ensayo mío -ensayo en el sentido ecuánime con que Montaigne primero definió el género, el de tentativa y hasta de experimento con determinadas propuestas destinadas a confrontar el juicio 
reflexivo ajeno, y haciéndolo siempre como hipótesis y nunca como paradigma-, en esta ponencia, digo, he ido todavía más lejos del tímido vocablo “apuntes", designando a esta intentona como "primeros apuntes".

El único propósito tras esta cautela ha sido el de acotar en extremo los primeros resultados - por lo mismo, necesariamente incipientes- de mis pretensiones por interpretar la Lima de Palma, contrastando planteamientos de dos significativos intelectuales del siglo XX: Raúl Porras Barrenechea, quien llamó a la capital "refugio y cúspide para tantos hombres de América", y aquella "Lima la horrible" como la denominó a secas un provocador de fuste como fue Sebastián Salazar Bondy. La empresa, como ven, es de mayor aliento que el de este esbozo inicial, por lo que seguiré en los próximos tiempos desarrollando el tema con la misma perseverancia que he puesto en estos párrafos harto insuficientes.

Advierto, sin embargo, que ya he cometido un primer desliz al decir "la Lima de Palma”. Esto es así porque, sencillamente, no hay una Lima de Palma, porque Lima y Palma son inextricables una del otro; porque Palma y Lima son como el reverbero mutuo de dos espejos que se funden en reflejos simultáneos; porque la obra de Palma es un ejercicio perpetuo de limeñidad, si por obra pensamos en su caso en aquella que, trascendiéndolo, ha devenido en legado literario universal, en el alegato acaso más distintivo de la peruanidad y en el testimonio acaso más veraz de la esencia misma limeña: las Tradiciones Peruanas.

Entrando así en materia, en el primero de mis apuntes debo repasar el registro de Sebastián Salazar Bondy sobre Lima o, dicho más propiamente, sobre las supuestas culpas de Ricardo Palma por las imágenes de esa Lima que Salazar embiste frontalmente, acusándolo de perpetuar la Arcadia Colonial. 
La primera observación es que las metáforas intencionalmente grises del discurso de Salazar sobre Lima -redactadas, reconozcámoslo, en prosa aguda, innegablemente refinada y pulcra- carecen, sin embargo, de un bagaje teórico fáctico que pudiera justificar el uso de esas opacidades, cuyo propósito sería el de vertebrar convicciones sólidas o, cuando menos, válidas en su acentuación contestataria. La base conceptual recordémoslo- de Lima la horrible, radica en la propuesta de una deformante Arcadia Colonial, en referencia a la infección con que Lima, según Salazar, contagia el espíritu anímico del país, socavándose a sí misma y a toda la nación con la corrosión del criollismo, la behetría del linaje, el cáncer del folclore, la degeneración del arte, de la literatura y hasta de la mujer limeña, la falsedad de su arquitectura y la aún mayor de las evocaciones del vals criollo, y de cuanto hubiere de igualmente deleznable detrás del limeñismo pasadista -que, según el raciocinio de Salazar, sería prácticamente todo lo que se respira en la capital-, rescatado, sin embargo, por la ciudad misma como su gallardete distintivo y redimido por Ricardo Palma como la divisa de la personalidad de Lima. Pero, dejemos más bien hablar al propio Sebastián Salazar Bondy, recogiendo algunos de sus propósitos más frontales dispersos por todas las páginas de su monografía, como una forma de recapitularlos para su más rápida comprensión ${ }^{1}$ :

\{El\} instinto de conservación, que ha librado a la aristocracia limeña del horrendo crepúsculo... no ha cedido en un punto en aquello que constituye su más preciado blasón: la segregación de la mayoría india y mestiza y, lo que es peor, pobre... Le ha fabricado, para conformarla, la fantasía de la Arcadia Colonial... y su artilugio criollista.

\footnotetext{
I Las citas de Lima la horrible provienen de la edición de 1964 publicada por Populibros Peruanos.
} 
La Arcadia Colonial es la envoltura patriótica y folclórica de un contrabando. Lima es por ella horrible, pero la validez de este calificativo depende de dónde nos situemos para juzgarla, qué código consultemos para medir sus defectos y vicios y a quiénes sentemos en el banquillo de los acusados.

A Lima le ha sido prodigada toda clase de elogios. Insoportables adjetivos de encomio han autorizado aun sus defectos, inventándosele así un reverberante abolengo que obceca la indiferencia con que tantas veces rehuyó la cita con el dramático país que fue incapaz de presidir con justicia.

Los frutos de tales (...) embelecos cuajaron, en el XVIII, en imágenes(...) de las que se apropiaron (...) corregidores y encomenderos. De ahí a nuestros días, la retórica ha ornamentado el cuento a gusto del colonizador y su heredero (...) Ricardo Palma resultó, enredado por su gracia, el más afortunado difusor de aquel estupefaciente literario. Su fórmula (...) fue: mezclar lo trágico y lo cómico, la historia con la mentira.

Es verdad que el autor de las Tradiciones Peruanas compuso una suerte de frágil y aldeana comedie humaine, pero no acertó a incluir en ella a nadie que por descontentadizo y libre quisiera sacudir el conformismo y trastrocar la deferencia debida a las instituciones. Respectivamente, su versión de los próceres de la Independencia estuvo morigerada por el adormecedor aroma de salones y alcobas virreinales. La invención colonial, de tanto éxito, acabó con su inicial propósito satírico, ciertamente demoledor. Es innegable que la tradición malogró a Palma para la historia (...) y que en vez de la realidad virreinal nos legó una teoría digresiva del mundo - del mundo limeño, se entiende, o del universal atisbado desde la estrecha mirilla pueblerina- que ahora es difícil reemplazar por otra general, científica. Tanta es nuestra pereza intelectual que estamos cómodamente sumidos en el congelado esquema de una quimera. El que no acepta la leyenda como heredad y los fantasmas que la pueblan como antepasados venerables, como larvas o manes, resulta para el consenso una rara avis, peligrosa y hasta de rapiña. 
Todo lo anterior carecería de importancia si el criollismo no contrabandeara la fantasía de la Arcadia Colonial. [...] La palabra criollo designa muchas cosas (...) Su significado actual es, sin embargo, limeño (...) de cualquier cuna (...) pero, a condición de que no sean indígenas. Criollo resulta así sinónimo de costumbrista (...) Nuestro costumbrismo (...) es totalitario. Abarca cocina, música, arquitectura, danza, deporte, farmacopea, urbanismo, lenguaje, poesía y religiosidad. $Y$ asimila, por el culto y la práctica, tanto al limeño viejo cuanto al recién venido (...) El criollismo vendría a ser, pues, el nacionalista limeño, o sea, un sucedáneo del verdadero nacionalismo.

$$
* * *
$$

En un segundo apunte observaría que, bien a pesar de que al comienzo de su texto Sebastián Salazar Bondy declara -y citoque "la época colonial, idealizada como Arcadia, no ha hallado todavía su juez, su crítico insobornable”; en sus últimas páginas afirma contradictoriamente -y vuelvo a citarlo- que "Lima tuvo su primicial reivindicador: (...) Manuel González Prada [...] su radical y anarquizante espíritu la emprendía, merced a un estilo claro, pulido y compacto, contra la usual retórica de las letras y la escena pública. O sea, contra Ricardo Palma, quizá a pesar de sí, demiurgo del colonialismo literario". Rematará Salazar estos juicios alegando que González Prada "sacudió el infundio palmiano".

Sin embargo, ante tanta diatriba contra Palma -habría que citar muchos otros párrafos-, Salazar intenta explicarse: "Cometemos aquí el sacrilegio de no ponderar su obra con la verbosa incondicionalidad que es usual. A fuerza de ingenio, paciencia y buen humor, Palma adobó el mito con el polvo de los archivos, pero sus personajes solo ocasionalmente son héroes, nunca rebeldes ni libertadores(...) Una galería de cortesanos respetuosos y respetables surgió de la pluma del gran escritor. 
Ni ellos ni sus acciones pusieron en peligro el fabuloso decorado de los representantes regios, de sus coquetas aunque púdicas mujeres, de sus clérigos menos licenciosos...".

Decía al inicio del apunte anterior que, en su persecución contestataria (que ya quisiera volteriana), Sebastián Salazar Bondy arremete contra Lima y contra Palma con opiniones que, lamentablemente, carecen del necesario anclaje en un determinado aparato crítico que pudiese demostrar con rigor académico lo que, por falta de este, deviene apenas en impresiones, conjeturas o comentarios sobre una Lima que aparece, así, finalmente caricaturada. La "teoría digresiva del mundo limeño" que le imputa a Palma, más que una teoría "difícil \{de\} reemplazar por otra general, científica", como lo afirma textualmente Salazar, resulta entonces ya no difícil sino inalcanzable porque, justamente, la propuesta no se sustenta en ninguna teoría "científica" para definir a Lima, como tampoco -dicho al paso- lograra hacerlo jamás González Prada, paradigma intelectual de Salazar, en las maledicientes incontinencias enderezadas contra Palma.

Lima la horrible resulta ser, pues, un libro hecho más que nada de supuestos que se diluyen en adjetivaciones, justamente por carecer de una teoría comparada resultante de una investigación social, política y cultural sobre la Lima pasada y presente y, para el caso, sobre el Perú en su conjunto, usando las herramientas críticas disponibles del momento -como podían haber sido determinadas propuestas de la Escuela de Francfort o de Herbert Marcuse, o las que asomaban en los años sesenta cuando Salazar escribe su texto-, instrumentos críticos, unos u otros, para analizar multidisciplinariamente las estructuras e ideologías de las sociedades humanas. La aplicación de tales investigaciones, a las que el autor sumaría sus propias hipótesis, habría resultado provechosa si, como lo 
pretendió Salazar, la intención de su contrapunteo crítico era deconstruir analíticamente las estructuras conceptuales de aquella Arcadia Colonial, para estar en condiciones de arrasarla. No habiendo logrado su propósito, el resultado es desolador: la "teoría digresiva" que Salazar le cuelga a Palma, irónicamente se revierte en su contra dando pie a que se aplique a su propia prestidigitación retórica, más aún cuando carecemos de cualquier concepto sobre esa teoría.

$$
* * *
$$

Cierto es también -y esto me lleva a mi tercer apunte- que, a primera vista, podría aparentemente emplearse estos mismos argumentos a los escritos de Raúl Porras Barrenechea sobre la Lima palmista, porque tampoco reposan en alguna teoría analítica determinada. Aunque intuyo que un pequeño detalle -que en este caso resulta abismal-distingue a Porras de Salazar: aquel no pretende clasificar moral o estéticamente a la ciudad, mientras que los planteamientos de este se dirigen justamente a enjuiciarla con esos valores -error en el que no habría incurrido de haber digerido algunas de las teorías señaladas. Más bien, apoyándose en sus investigaciones Porras procura ilustrar cómo Ricardo Palma relata Lima, cómo la va contando a medida que transcribe las tradiciones urbanas de los tiempos de la colonia y de los iniciales de la república. El adjetivo "horrible", en cambio, permea íntegramente la diacrítica del texto de Salazar al presentarse como un contundente juicio de valor sobre la ciudad, reflejo casi maquinal de una cerrazón confrontacional que no encontramos ni siquiera en César Moro, cuyo humor detrás del calificativo de "Lima la horrible", que Salazar le tomaría prestado para su ensayo, no deriva de la mordaz referencia de Moro para la datación de La tortuga ecuestre, pues el sobrenombre de "horrible" resulta ser, apenas, una puya sarcástica para epatar al lector más que para asentar un despecho deliberado. 
Intentar una cirugía ideológica al imaginario colectivo para extirparle sus fantasmas, es como pretender contener el reflujo de la marea sorbiéndola desde la orilla: hay espectros que pueblan las sombras y resquicios de nuestra memoria que jamás podrán borrarse del subconsciente, pues nacieron en un pretérito inmemorial en donde nada es verídico pero tampoco apócrifo. El análisis contracultural emprendido por Salazar termina siendo, por ello, una conjetura antes que una rebeldía, lo que resulta lamentable porque la audacia del proyecto siempre estuvo entre las páginas de su ensayo, porque al andamiaje de la insubordinación que Salazar intentaba articular, apenas le faltaba la utilería teórica con la que hubiese podido comprobar su denuncia del "hispanismo meramente tauromáquico y flamenco", según sus propias palabras, que alimentaría la insoportable arcadia limeña astutamente ingeniada, según él, por Ricardo Palma. Queda de todo ello apenas un título, Lima la horrible, suficientemente abrupto como para haberse convertido, con el tiempo, en una suerte de banal locución interjectiva en boga para referirse a la capital, a menudo en boca de gentes que ni siquiera han leído el libro pero que repiten el estribillo por mera inercia, o para mejor remarcar frívolamente su preferencia por "el Perú profundo" expresión que en esas mismas bocas no está exenta de algún pintoresquismo andino- frente a la execrable Lima.

$$
* * *
$$

El cuarto apunte se inicia con un necesario cotejo: comparar y contraponer, para mejor contrastar, aquella atormentada mirada sobre Lima en la pluma de Sebastián Salazar Bondy, con la perspectiva reflexivamente más serena, por no decir más rigurosa, de Raúl Porras Barrenechea. Pero al hacerlo, tengamos presente lo siguiente: no es que Porras persiguiera, a través de la Lima retratada por Palma, enfoques edulcorados de nuestra capital cuando, por ejemplo, recuerda el elogio de Rubén Darío -"Santiago es la 
fuerza, Lima es la gracia"-, la glorificación de Vicuña Mackenna - "la primera ciudad de Sudamérica y la segunda de España” o la aclamación de Rafael Heliodoro Valle: "Ciudad de luz, de niebla y de rocío", acentuando así la "mimosa frase proverbial", al decir del propio Porras, de la cursilería aquella coreada, también con sorna, por Palma: "Lima, quien no te ve no te estima". Bien por el contrario, como implacable historiador que siempre fue, nunca propenso a la hipérbole y siempre hostil al dictamen indocumentado, al escribir Porras sobre la mirada palmista de Lima jugará algunas veces con el lector sugiriendo, por ejemplo, en desafiante y travieso acertijo, que: "La Ciudad de los Reyes... la fundaron en colaboración don Francisco Pizarro y don Ricardo Palma”. Esto hace que, como lo dijo Porras (que también lo habría suscrito Salazar), Ricardo Palma sea "el creador de la leyenda de la ciudad". Pero las semejanzas se detienen allí, porque Porras nunca verá sinonimia alguna entre leyenda y mentira, puesto que la historia -y lo comprobará cada vez que glose a Palma- bien puede nutrirse de los mitos y fábulas con que se edifican las leyendas, mientras que Salazar, mediante un sofisma deductivo consciente, concluye que la leyenda es solo mentira, jamás historia, que es apenas un trampantojo del pasado o, más precisamente, el desvarío con que se construye la Arcadia Colonial, con lo cual se comprueba que la tradición, retoño de la leyenda, es poco menos que un embuste deletéreo.

$$
* * *
$$

En el quinto apunte debo hacer una recapitulación de un par de observaciones de Raúl Porras Barrenechea, semejante a la de la nota inicial sobre las ideas centrales de la Arcadia Colonial de Sebastián Salazar Bondy; esto nos permitirá ponderar a contraluz los contrastes interpretativos del tradicionista en las aproximaciones de ambos críticos. Porras dirá2:

2 Las citas de Raúl Porras Barrenechea provienen de los siguientes textos: 
Añorando y riendo escribieron los más auténticos limeñistas, los intérpretes y los evocadores de la ciudad, aquellos por quienes esta vive en la historia y en la literatura. El más glorioso de todos, el que unió en más sutil alianza tradición e ingenio, lo perdurable y lo efímero del alma limeña, fue don Ricardo Palma. Se confunden de tal modo su picardía con la picardía de la ciudad, la tradición que él noveló con la historia auténtica, que no se sabe ya con fijeza si fue la ciudad la que lo forjó o si él le ha prestado su endiablada travesura...

Desde al arrabal o el atrio de la iglesia, desde el coso popular o el patio de la escuela, desde la taberna o el corrillo estudiantil, ascienden y toman carta de ciudadanía en la literatura una serie de vocablos sandungueros y mestizos, engendrados por la cacharrería o el donaire callejo (...) Y todo esto, porque Palma poseía (...) el don descriptivo para el retrato físico y psicológico, admirable facilidad y naturalidad para el diálogo.

Criollo es al cabo lo nacido y criado en la tierra y calentado por la emoción popular, ya sea esta costeña o serrana, pero de todos modos expresión de un alma mestiza, de una casta vieja y nueva a la vez, surgida de la fusión de lo propio y de lo importado y por ello alegre y melancólica a un tiempo [...] A pesar de los distingos especiosos étnicos, sociales o artísticos, en Palma hallamos inconfundiblemente desparramada en sus tradiciones, en el lenguaje y en el ambiente, la sensación del más auténtico criollismo peruano.

Palma era la tradición y en la tradición estaba la mejor raíz del limeñismo. El acercamiento era esperable [...] las tradiciones son

Pequeña antología de Lima; colección Peruanos Imprescindibles, Libro 12, Orbis Ventures S.A.C., Lima 2005; Lima, la tradición y el tiempo, Raúl Porras Barrenechea; estudio y recopilación de Jesús Cabel; Editorial Universitaria de la Universidad Ricardo Palma, Lima, 2008; Libro de homenaje a Raúl Porras Barrenechea. Testimonios; IRPB, Lima, 2008; Antología de Raúl Porras, de Jorge Puccinelli; IRPB, Lima, 2011. 
nuestra gran epopeya humorística, nuestra comedia humana con sus mil personajes (...) la síntesis de nuestra vida nacional [...] un género literario propio e inconfundible (...) producto genuino, limeño y criollo [...] La aptitud limeña para la sátira, es ya un lugar común en la historia literaria peruana (...) Palma, el espíritu representativo de nuestra literatura, tenía que ser necesariamente burlón [...] Miguel de Unamuno lo ha llamado el primer ironista de la lengua.

Raúl Porras Barrenechea escribió extensamente sobre Ricardo Palma a lo largo de su trayectoria intelectual, regresando periódicamente al tradicionista para seguir interpretándolo o para revisar nuevamente determinados rincones desapercibidos de su obra. Un libro como Pequeña antología de Lima, ya de 1935, y ensayos tales como "Palma y lo criollo", "Palma satírico" y "Palma romántico", corroboran la permanente inclinación del más hondo de nuestros historiadores por "el más grande forjador de peruanidad", como llegó a calificar al tradicionista en palabras que, además, recuerdan lo que fue para Porras vocación primigenia, a veces relegada por sus exégetas: la literatura.

Pero en todos sus escritos sobre Ricardo Palma, jamás Porras se desvió de la autenticidad documental que pudiese sustentar, por la vía de la oralidad informada o el dato preciso de la tinta, lo que aquel acopió en sus Tradiciones. Por tanto, nunca rebuscó Porras intencionalmente la galantería rubendariana o cualquier otra sobre la capital peruana retratada por Palma, para exhibirlas como pruebas de una cornucopia limeña. Por el contrario, escribió sobre la Lima palmista con la certitud de que no todo juicio sobre la ciudad de antaño había sido siempre épico, poético o idílico, dígase arcádico. Ya se refirió Porras, de distintas maneras y en diversas ocasiones, a esa Lima indicando que $-y$ lo cito-: “...sus detractores o censores apasionados (...) han contribuido (...)a modelar el juicio sobre nuestra ciudad (...) y descubrir defectos tan significativos como muchas cualidades 
(...) trozos lapidarios de González Prada (...) y de Federico More, en contra de Lima. Y, haciéndoles coro, Groussac (...) y (...) Concolorcorvo". Jamás, pues, ignoró Porras que la Lima virreinal -aquella dama desdentada, malhumorada, desaliñada y envejecida aunque siempre coqueta que, según Salazar, adormece a la capital republicana con las tradiciones fantaseadas por Palma- no fue solo boato y esplendor. Siempre tuvo presente que a la presumida Lima colonial también la plagaban mendigos y le sobraban esclavos, efectos de una vida licenciosa que atizaba la holgazanería, la intriga y aquellos otros vicios profanos de una mundanería libertina, todo lo cual "le dio al limeño su complicada indecisión e hizo de Lima la ciudad típicamente mestiza", según la opinión de Waldo Frank que recogiera Porras. La decepción que nutre la Arcadia Colonial de Salazar no nace, entonces, del desencanto, pues el desencanto es siempre la desilusión con una verdad desmoronada. Su arcadia es más bien una inferencia que, aunque no comprobada, explica, a su juicio, los avatares del retraso y la miseria social que agobian al Perú, tanto como los remotos atavismos que lastran a su morador.

Así, pues, Ricardo Palma, cuyo fervor por las tradiciones limeñas lo llevan a transcribirlas devotamente, se convierte, según la curiosa ecuación arcádica de Sebastián Salazar Bondy, en el reo culpable de todas las malandanzas nacionales, mientras que a los ojos de Raúl Porras Barrenechea, ese mismo fervor es el corolario lógico de aquella devoción que el tradicionista profesa por Lima. Ante ello, exasperado con la apología de Palma, no le quedará a Salazar sino emprenderla también con Porras lamentando -y cito-: "que se embriagara de historia para adormecer su vibrante actualidad". Quedaría así probado que Salazar nunca llegó a entender que toda devoción es primitiva, y que la de Palma por Lima no podía ser la excepción. Y más aún: jamás entendió que en ese primitivismo querendón, por llamarlo de algún modo, en esa suerte de patrioterismo 
parroquial, en esa especie de permanente trance espiritual con la capital, verdecería la prosopopeya palmista de Lima en toda su inimitable grandilocuencia, pero no como nostalgia del pasado, es decir, como arcadia colonial, sino como simple acto de fe.

En el prólogo introductorio que Raúl Porras Barrenechea escribiera al Epistolario de Ricardo Palma publicado por primera vez en 1949, el gran historiador concluiría con una meditación que, a mi parecer, sintetiza lo que el tradicionista representa para el Perú: "Palma surge -dirá Porras-en el dintel del siglo XIX como el Inca Garcilaso en los adarves del siglo XVI. Se debate entre dos mundos contrapuestos. Garcilaso se halló entre el Incario y la Conquista como Palma entre la Colonia y la República. Palma se siente americano como Garcilaso se sentía español, porque ESE era el signo irrevertible del tiempo, pero ambos guardan un venero de gratitud y de nostalgia para la época desaparecida y tratan de interpretar y de guardar su mensaje irrestañable".

$$
* * *
$$

A partir de estos cinco primeros apuntes sobre la Lima que inmortalizó don Ricardo Palma en sus tradiciones, revisada por dos singulares pensadores como fueron Raúl Porras Barrenechea y Sebastián Salazar Bondy, me propongo profundizar más adelante, como ya lo manifesté, en el análisis de las premisas con que ambos desentrañaron la substancia de la capital. Lo intentaré, insisto, apenas como un ensayo o tentativa de elucidación de los escritos de Palma, aunque sospechando simultáneamente de la improbabilidad que tales resultados contribuyan realmente a una aún mayor apreciación del indubitable aporte de Palma a la construcción de este país nuestro que espera, impaciente, devenir algún día en nación. Mi recelo anticipado es por aquella rotunda reflexión que don Estuardo Núñez formulara en su prólogo al primer número de Aula Palma -ese tan loable esfuerzo 
editorial, igualmente de don Manuel Pantigoso, por mantener la vigencia del tradicionista-, al advertir con severidad que, si bien esta publicación -y lo cito- ha "contado con muchos y brillantes estudios sobre la figura y obra de Palma(...) también es notorio que se han repetido y utilizado muchos lugares comunes y frases hechas, producto de un facilismo cómodo que solo ha servido para redactar ligeras y redundantes apreciaciones, reseñas superficiales o banales rememoraciones anuales de tipo periodístico, basados únicamente en aquellos trabajos fundamentales de las generaciones anteriores". Palabras tan admonitorias han de recordarnos siempre el enorme desafío que representa escribir sobre la heredad palmista.

Al tiempo de reiterar mi gratitud a las autoridades del Instituto Ricardo Palma por acogerme en este cenáculo, y de renovar mi compromiso de contribuir a la perduración de la obra de nuestro tradicionista, permítanme concluir con una publicidad que, de algún modo, está vinculada a lo que he estado repasando. El año próximo se conmemora el cincuentenario de la fundación del Instituto Raúl Porras Barrenechea que, como se sabe, es el Centro de Altos Estudios e Investigaciones Peruanas de la Universidad Nacional Mayor de San Marcos. A lo largo del 2014 pretendo, en tanto que Director de ese Instituto, que se realicen diversas actividades académicas conmemorativas alrededor de las disciplinas que fueron propias del maestro Porras: historia; relaciones internacionales y diplomacia; literatura; docencia y educación; geografía; periodismo. Coincidentemente, el año próximo también se cumplen cincuenta años de la aparición de Lima, la horrible, entre otras fechas emblemáticas que se recordarán apropiadamente. Así, pues, el Instituto Porras organizará un coloquio sobre ese libro de Sebastián Salazar Bondy, para que se aborde de manera pluridisciplinaria la vigencia de los postulados de Ricardo Palma, de Raúl Porras Barrenechea y del propio Sebastián Salazar Bondy sobre Lima. 